\title{
Flood hazard mitigation by actions in the hillslopes: does the context change the assessment of efficiency?
}

\author{
Saâdia Benmamar ${ }^{1}$, Christine Poulard ${ }^{2}$,, Pascal Breil ${ }^{2}$, Etienne Leblois ${ }^{2}$, Jean-Baptiste Faure ${ }^{2}$ and André Paquier ${ }^{2}$ \\ ${ }^{1}$ École Nationale Polytechnique, Laboratoire de Recherches Sciences de l'Eau, 10 avenue H. Badi BP 182 Harrach, Algiers, Algeria \\ ${ }^{2}$ Irstea, Hydrology-Hydraulics Research Unit, 5 rue de la Doua CS 70077, 69626 Villeurbanne Cedex, France
}

\begin{abstract}
For sustainable and integrated flood management, small actions in the hillslopes and non-structural measures appear interesting, either to diminish the need for large flood mitigation infrastructures (whether sewerage networks or hydraulic structures in the river - which may have severe impact on the river ecosystems), or as complementary to these structures. However, the effect on flood mitigation of land-use modification and small storage or runoff control facilities is still debated in scientific literature. The effect of various structures spread over the catchment is difficult to assess, and hazardous to generalize from one studied catchment to another, which explains why the debate is still open. This study contributes to identify context features that could also explain constrasting results. Focusing on a West-Mediterranean Northern and Southern countries literature, we compare first traditionnal and modern hillslope actions against runoff in both countries. Then, we search in the physical contexts differences that might explain why actions in the hillslopes are more studied in Europe than in Maghreb. But the priorities of national or regional policies also explain differences in the perception of efficiency: the interest of hillslope actions is different if the aim is to limit erosion and pollutant transfer and/or to mitigate large floods. Pollution and how ecological status is taken into account in flood mitigation project assessment are also crucial points.
\end{abstract}

For sustainable and integrated flood management, small actions in the hillslopes and non-structural measures appear interesting, either to diminish the need for large flood mitigation infrastructures (whether sewerage networks or hydraulic structures in the river which may have severe impact on the river ecosystems), or as complementary to these structures.

However, the effect on flood mitigation of land-use modification and small storage or runoff control facilities is still debated in scientific literature. The effect of various structures spread over the catchment is difficult to assess, and hazardous to generalize from one studied catchment to another, which explains why the debate is still open [7].

Flood management is a field of investigation with scientific difficulties (hazard characterization and flow dynamics) but also human, economic and political issues (how to reconcile the natural hazard sand development, on which projects funding prioritization criteria flood prevention). The focus is often on urban and suburban areas, because most of the issues are concentrated, and these places are constantly changing [6].

- The density and the size of the cities continue to grow while the hydraulic capacity of the sewerage networks deteriorates.

\footnotetext{
${ }^{\mathrm{a}}$ Corresponding author: Christine.poulard@irstea.fr
}

- Waterproofing of soil due to the facilities (buildings, roads, car parks...) limit rainfall infiltration into the soil and accentuate runoff. This often causes the saturation and discharge of stormwater sewerage systems. The result is more or less important and often rapid flow in the streets.

It must therefore be distinguished between:

- flooding caused by rivers overflow,

- what is truly the realm of urban runoff and suburban runoff.

\section{Principle of development on flood risk management}

The possible actions for flood risk management can be grouped are often divided in structural and nonstructural measures.

Structural measures aim at managing flood volumes in space and time to protect stakes, using retention structures, river training and levees (figure 1). Their design must achieve a compromise between flood reduction, expressed in terms of reduction of Expected Annual Damages, and other constraints, like ecosystem conservation, landscape and acceptability, and be fair to 
all the inhabitants of the catchment - you should not protect a community at the expense of another one.

This communication focuses on the specific issue of structural measures in the hillslopes, upstream the rivers, either to manage special flood hazard due to surface runoff, or to contribute to flood hazard mitigation farther downstream in complementarity with larger structures (figure 1).

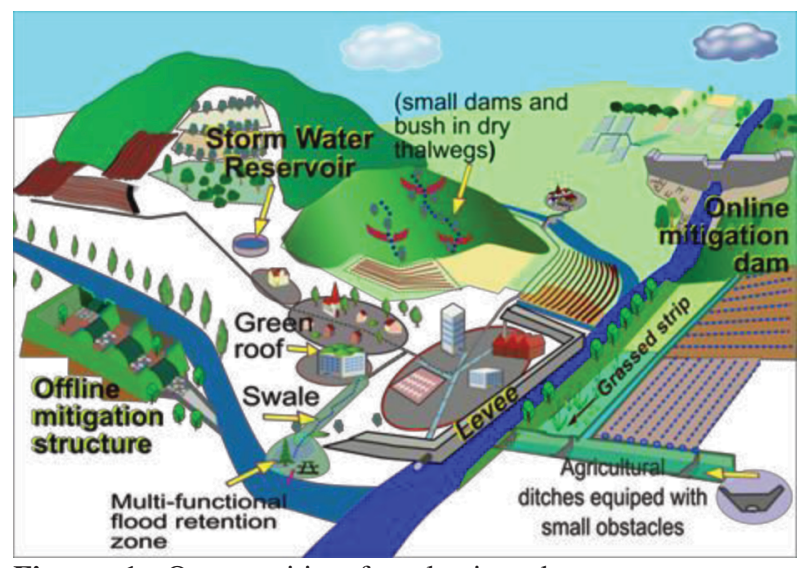

Figure 1. Opportunities for slowing down or temporary storage using flow limitation in a catchment

Structural measures must be designed in complementarity with non-structural measures, also aiming at reducing the damages by reducing the vulnerability and enhancing preparedness (planning documents and other information, flood warning systems, houses retrofitting or constructional features imposed to new buildings...).

\section{Problems in Algerian cities}

Algeria is one of the southern Mediterranean countries which suffered from devastating floods. While in the past these floods were especially due to overflows of major rivers in large agricultural plains (Chellif, Soummam, Sebaou ...), since thirty years they have mainly affected major cities and urban centers ; they have caused many casualties and considerable material damages (Bab El Oued floods in 2001 and 2013; Ghardaia, 2008; Annaba in September 2009 and February 2015, El Taraf, 2012, Algiers, 2015 ...) [2, 6].

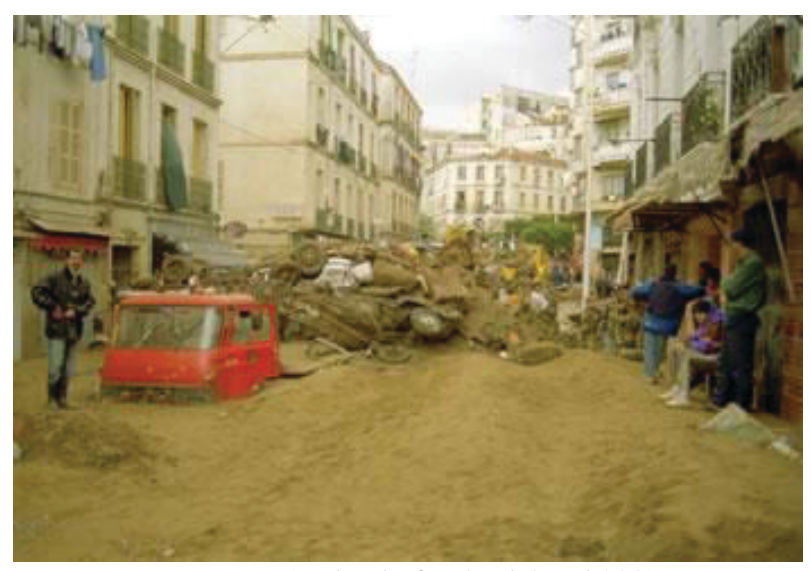

Photo 1. Flood of Bab El Oued 2001
In current situation, Algeria is very exposed to the flood risk, whether by river overflow or sewerage network outflow

Whether in small or large rivers, flow is hampered by reductions in flow sections due to uncontrolled, embankments and illegal occupations of the bed and the banks, and to many linear infrastructures (roads, railways,...).

The sewerage networks have generally been designed for a return period of 2 years in previous masterplans. Low concentration time and the steep slopes of some watersheds where urbanization is highly developed without preserving the lines of flow can be originally flooding in a fast and violent way, that can cause disasters. Overflows are generated by intense showers of short duration; they are aggravated by conditions of saturation of soils following a succession of rainy episodes leading to strong overlapping of rain, and that can cause mudslides. In low slope areas, where drainage runoff is using pumping stations, inadequate pumping capacity also leads to frequent overflows.

\section{Current techniques in the management of stormwater in Algerian cities}

The Algerian authorities, overwhelmed by the magnitude of the problem of urban water and seeking solutions, proceeded with the creation of urban water management agencies for the most important cities of the country, with mixed partnership contracts. Solutions presented as innovations appear rather as old-fashioned, classical methods: rainwater is merely expected to be managed through gutters or pipes towards one or more outlets, and released into the environment after temporary storage and treatment in a sewage plant. The sustainability and actual cost of these proposals should be assessed more carefully.

When a sewerage system is defective, the classic solution adopted is repair or restructure by combining the following [4]:

- Strengthen, Renew or double the sections of the existing network: eg. duplication collector OuedM'Kacel at Bab el Oued carried out following the flooding of 2001. It will allow to drain storm water to the sea, while wastewater will flow into a collector to be derived to the East of the capital, to Baraki or Reghaia sewerage treatment plants.

- Building of new culverts (e.g. gutters stairs installed throughout Algerian territory).

- Oversized and expensive concrete pipes, which often displace the problem of floods from one locality to another, without truly solving the problem of stormwater.

Developments on the rivers are:

- Development of dikes sidewalls and the growing upstream urban areas;

- Recalibration of the watercourse. 
The level of protection of the facilities would decrease: a return period of 50 instead of 100,10 instead of 20 years and 5 instead of 10 years.

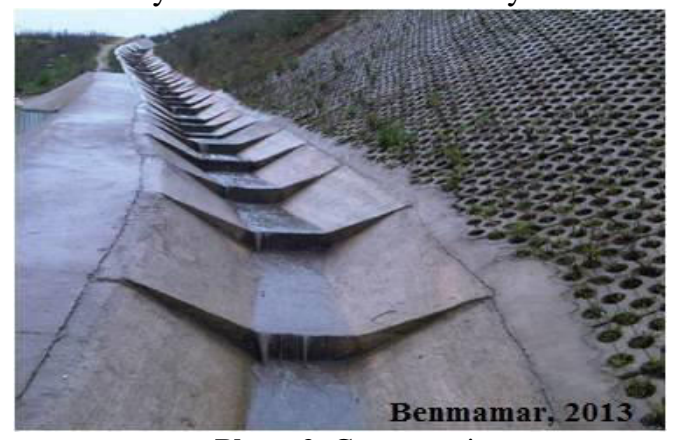

Photo 2. Gutters stairs

These methods of urban drainage involve equipping storm basin with weirs that directly reject excess inflows into the natural environment.

So, the issue here is to investigate why "best management practices", or "Sustainable urban drainage systems", often presented in developed countries as more appropriate, more environmentally friendly and cheaper, have not spread to Algeria.

\section{Sustainable urban drainage systems}

Paradoxically, urban stormwater management techniques seem inspired by ancestral techniques in arid areas around the world (eg: ancestral hydraulic system of Ghardaia).

In recent decades many countries have adopted alternative methods stormwater management [3].

The issue of Sustainable urban drainage systems is to relieve existing networks by storing and controlling stormwater upstream, so avoiding overflows, firstly to limit urban local inundations, and secondly to reduce polluting overflows in the natural watercourses. They differ from the traditional buried networks by their ability to blend into the urban landscape, in the form of swales, ditches, trenches, soakaways, basin, green roofs (Figure 1) [1, 7, 8].

In France, SUDs are presented as efficient tools to relieve sewerage networks, especially when local regulations impose stormwater outflows limits to newly build areas: owners have to deal with their stormwater, so that no extra constraint is put to the community's network in spite of this additional impervious area. In parallel with spreading and the diversification of these techniques, stormwater management is becoming more and more compulsory [5].

Comparing cost and benefits associated with small structures is not easy, because they involve many different small structures, and different actors (private land owners with their own small retention systems, municipality and State services in charge of streets, roads and underground network...). Maintenance is also difficult ot assess a priori and to carry out, because the structures have many private and public owners. On the contrary, classic design methods have validated dedicated tools and well-identified persons in charge of maintenance.

To comprehensively evaluate the costs, the following points should also be taken into account:

- The damage reduction for small floods, even local, individually inexpensive may account for much of the expected annual damages because of their frequent occurrence ;

- The ecological consequences of overflows on the natural river functions, regarding the local and national environmental policies (see for instance the Water Framework Directive of the European Union, imposing to preserve and improve the ecological status of rivers).

Many obstacles remain:

- Feasibility, design, and costs repartition of Sustainable urban drainage systems are casedependent. A specific detailed study is necessary, for each project; diversity of structures and their small size enhances the difficulty of design and assessment. Discussions may arise about the actual costs for the public project-manager. Muti-objective projects are also more difficult to assess,

- A real lack of information regarding these techniques and potentialities among stakeholders likely to propose, prescribe them or use them,

- Need of expertise for Sustainable urban drainage systems: the methodology and tools are less straightforward than for pipes design; it is still in part a research field. Working methods must be adapted, training must be available. Feed-back must also be shared,

- Not all the stakeholders have interests in these techniques (traditional consultants, private companies or persons who do not want to support the cost of rainfall management on their plot and prefer collective solutions....),

- Difficulties of maintenance of rainwater management structures sharing other functions, with the problem of identifying the departments in charge of maintenance, and responsible in case of incident (grassed swales to be tended as public gardens, water retention on sports or recreational facilities, porous roadsides and pavements where rainwater infiltrates ...).

\section{Conclusion}

The use of Sustainable urban drainage systems should be an integral part of any development's surface water management strategy. This should provide a basis for replicating the response of a catchment and its surfaces by mimicking, to some extent, the behaviour of surface water on the developed site as if it had remained undeveloped.

Integrated flood management offers many opportunities for the development of water supply, both 
locally and regionally. They require more studies, including innovative developments, and careful comprehensive way: they do not only concern large floods, but may also help manage small local problems, and can bring multi-objective solutions, including public awareness (with visible facilities) and resource management (with storages and infiltrations). This may contribute to necessary adaptations to drought that Algeria suffered for many decades and risk likely to worsen in the eventuallity of a global climate change.

Climatic specificities could be a possible explanation to the lack of interest for SUDs in northern Africa, and yet they are implemented in mediteranean countries of southern Europe ([9]), with a similar climate. So, the rarity of SUDs in Algeria is more likely due to a deficit in the transmission of information, and to the difficulty of the implementation of this approach. Indeed, the design of SUDs cannot be reduced to application of guidelines with the help of standard design tools: it is by nature experimental, and requires a specific, thorough study to identify the flow paths and the opportunities to modify them. The techniques must be selected and adapted to each case. Even in the countries where SUDs alredy exist, a new implementation requires to accept novelty and experimental designs (in partnership with universities or not), with no full guarantee of success. In an area with little or no experience of SUDs, implementation is bound to be even more difficult : feed-back information from other countries are invaluable, but the approach and its techniques have to be adapted to local conditions and reglementation. Water storage and infiltration enhancement can be a key element for SUDs ([8]), and could be very interesting in particular in the Algerian context. Furthermore, beyond stormwater management itself, SUDs have other advantages : pollution reduction (by limiting the number of sewerage overflows into the rivers), landscape improvement and risk culture enhancement (by re-introducting stormwater and watergardens on the surface). Whether these features are taken into account or not in assessment will change significantly the interest of SUDs. So, investigation of SUDs should not focus on hydrology alone ; in particular, reglementations - in particular on water quality and river ecosystems status- appear powerful drivers of future research and tests on SUDs.

\section{References}

1 Azzout Y., Barraud S., Cres F.N., Alfakih E., (1994) Les techniques alternatives en assainissement pluvial, Ed. Tech et Doc, Lavoisier, 372 pages, 1994.

2 Bahlouli, L., (2009). Crues et inondations en Algérie. Actes de l'atelier scientifique et technique sur " L'Outil spatial au service du développement », pp. 17-25, Alger 28-29 mars.

3 Chocat B., (1997). Encyclopédie de 1'Hydrologie Urbaine et de l'Assainissement, Edition Lavoisier Tech \& Doc. maintenance. The issue is also to assess their effects in a

4 Le Jallé C. (2013). La gestion des eaux pluviales (GEP) en milieu urbain dans les pays en développement . Ps-Eau, 38pages.

5 Maigne, J. (2006). La gestion durable des techniques Alternatives en assainissement pluvial. Synthese technique, ENGREF Centre de Montpellier, 14pages.

6 Menad W., (2012) «Risques de crue et de ruissellement superficiel en métropole méditerranéenne : cas de la partie ouest du Grand Alger ». Thèse De Doctorat en Géographie de l'université Paris Diderot - Paris 7.

7 Poulard-Semra C., Berthier E., Breil P., Labbas M., Henine H., Hauchard E., Radzicki K., (2013). Managing rainwater all the way down: what urban and rural practitioners can teach one another and do together. Novatech

8 Poulard C., Szczesny J., Witkowska H. Radzicki K. (2005). Dynamic Slowdown: A flood mitigation strategy complying with the Integrated Management concept - Implementation in a small mountainous catchment. Journal of River Basin Management, 3(2), $75-85$.

9 Perales-Momparler, S., et al. (2014). SuDS efficiency during the start-up period under mediterranean climatic conditions. Clean - Soil, Air, Water 42(2): 178-186. 